\title{
Height-Diameter Allometry for Tree Species in Tanzania Mainland
}

\author{
W. A. Mugasha $\mathbb{D}^{1},{ }^{1}$ E. W. Mauya, ${ }^{2}$ A. M. Njana, ${ }^{3}$ K. Karlsson, ${ }^{4}$ \\ R. E. Malimbwi, ${ }^{1}$ and S. Ernest ${ }^{5}$ \\ ${ }^{1}$ Department of Forest Resources Assessment and Management, College of Forestry, Wildlife and Tourism, \\ Sokoine University of Agriculture, Box 3013, Morogoro, Tanzania \\ ${ }^{2}$ Department of Forest Engineering and Wood Sciences, College of Forestry, Wildlife and Tourism, \\ Sokoine University of Agriculture, Box 3012, Morogoro, Tanzania \\ ${ }^{3}$ National Carbon Monitoring Centre, Box 3013, Morogoro, Tanzania \\ ${ }^{4}$ Natural Resource Institute of Finland (Luke), Latokartanonkaari 9, FI-00790 Helsinki, Finland \\ ${ }^{5}$ Tanzania Forest Research Institute, Box 1854, Morogoro, Tanzania
}

Correspondence should be addressed to W. A. Mugasha; wilmugasha@gmail.com

Received 21 December 2018; Revised 19 February 2019; Accepted 27 February 2019; Published 21 April 2019

Academic Editor: Guy R. Larocque

Copyright (C) 2019 W. A. Mugasha et al. This is an open access article distributed under the Creative Commons Attribution License, which permits unrestricted use, distribution, and reproduction in any medium, provided the original work is properly cited.

Total tree height $(H)$ and diameter at beast height $(D)$ are important independent variables in predicting volume, biomass, and other forest stand attributes. However, unlike $D$ measurement, which is easy to measure with high accuracy, $H$ measurement is laborious. This study, therefore, developed $H$-D relationships for ten different forest types in Tanzania Mainland. Extents in which climate and forest stand variables explain the variation in $H-D$ allometry were also assessed. A total of 31782 sample trees covering miombo woodlands, humid montane, lowland forests, bushlands, grasslands, mangroves, cultivated land, wetlands forests, and pines and Eucalyptus species plantations were used for model development. The $H$ estimating model without climate and forest stand variables referred herein as "base model" was first developed followed by "generalized model" which included climate and stand variables. All the data were fitted using nonlinear mixed effect modelling approach. Results indicated that generalized $H$ estimating models had better fit than the base models. We therefore confirm a significant contribution of climate and forest structure variables in improving $H-D$ allometry. Among the forest structure variables, basal area $(B A)$ was far more important explanatory variable than other variables. In addition, it was found that the mean tree $H$ tends to increase with the increase of mean precipitation $\left(P R_{A}\right)$. We therefore conclude that forest specific generalized $H$ model is to be applied when predicting $H$. When forest type information is not available, generalized regional model may be applied. Base model may be applied when forest stand or climate information are missing.

\section{Introduction}

Diameter at breast height $(D)$ and tree height $(H)$ are among the important single tree parameters that describe forest structure and other forest characteristics [1-3]. Most tree variables, which are difficult to measure directly such as tree biomass and volume, are highly correlated with $D$ and $H$ $[1,4]$. Consequently, single tree biomass and volume are estimated by means of allometric models which use $D$ and $H$ as predictor variables. On the other hand, these parameters are also highly correlated. A good example is the relationships between $H$ and $D, D$ and crown diameter, and $D$ and stem height [4-7].

Often, $H$ has been excluded and only $D$ or a combination of $D$ and wood basic density is often applied to estimate biomass [8-10]. This assumes that the ratio of $H-D$, stem taper, and crown mass fraction is constant from smaller to larger trees. However, this assumption may result in systematic error for biomass and other stand level variables estimates since the relationship between $H$ and $D$ is not linear [3]. This is because in tropics $H-D$ relationship varies within the same species with different sizes, stand density, 
species composition, and site conditions $[1,2]$. In addition, while $D$ increases at a more or less constant rate until the tree is lost to mortality, $H$ normally reaches an upper limit asymptotically [11]. Consequently, various $H$ patterns affect other tree variable such as individual tree biomass and volume $[9,12,13]$. A good example is the reported reduction of allometric model standard error and relative root mean square error from $357 \mathrm{~kg}$ to $228 \mathrm{~kg}$ and from $47 \%$ to $33 \%$ when applying biomass and volume allometric equation for miombo woodlands of Tanzania Mainland, respectively, with $D$ as sole predictor and with both $D$ and $H$ as predictor variables $[4,14]$.

Conventionally, when carrying out forest inventory all trees in sample plots are measured for $D$ and few sample trees are measured for $H$ [15]. The measured sample trees are used to develop simple $H-D$ equations and applied to estimate $H$ of unmeasured trees. This approach is often used because measuring $H$ of all trees is laborious and time consuming especially in the tropical forests. The amount of work involved is aggravated by situations encountered in the field such as steep terrain, wide tree crown, and obstruction of tree tops by other trees crowns and leaning trees $[16,17]$. Advantage of this approach is that it takes consideration of site conditions, e.g., climate and structural variation at plot level. However, often, the number of sample trees is inadequate to capture the $H$ - $D$ allometry variations which may jeopardize the precision and accuracy of estimated $H$ and other associated forest stand parameters such as volume and biomass (e.g., [8]). Such $H$ estimating models which utilize only $D$ have been applied for decades $[1,18-21]$. Studies have reported that $H-D$ allometry is regulated by other factors, particularly abiotic factors such as soil nutrients, depth, and availability of water and biotic factors such as those describing the interactions of trees, e.g., competition for soil and light resources [2, 22-24]. These factors have been reported to trigger tree species specific phenotypic responses which affect allocation of biomass in tree parts. Irrespective of the reported significant effects of abiotic factors in $H-D$, there are a limited number of studies particularly in the tropical forests of Tanzania which have attempted to report the effect of abiotic factors on the tree $H$ $D$ relationship. In this study we consider that in addition to $D$, $H$ is also modulated by forest structure and climate variable.

At local scale where the climate gradient is relatively negligible, precipitation and temperature at spatial scale may not have effect on $H$. At large scale where climate variation is substantial there is indication that $H-D$ allometry also varies significantly among sites [2]. It has been shown that environmental resources especially water affect carbon allocation in tree compartments which may eventually affect $H-D$ allometry. For example, Ledo et al. [22] have reported rootshoot ratio to decrease with the increase in water stress. It has been further reported that maximum attained $H$ corresponds to amount of precipitation while for $D$ irregular pattern has been observed [25, 26]. In Tanzania Mainland where in most cases altitude coincides with moisture availability and precipitation, trees found in miombo woodlands at an altitude ranging from $300 \mathrm{~m}$ to $1100 \mathrm{~m}$, on average, are shorter than trees in humid montane forest found at an altitude above $1000 \mathrm{~m}$ [27, 28]. Despite such remarkable and obvious effect of climate and other associated abiotic factor, to date, there is no study which has attempted to report evidence suggesting the effect of climate on both $H$ and $D$ simultaneously in the miombo woodlands and other vegetation types in Tanzania. On the other hand, forest stand variables which describe density, e.g., basal area per unit area $\left(B A ; \mathrm{m}^{2} \mathrm{ha}^{-1}\right)$, may vary considerably within a given site compared to precipitation. The effect of forest stands variables on $H-D$ allometry had been reported elsewhere [29]. It is well known that trees of the same size in diameter growing in a dense stand are taller compared to tree growing in less dense stand [29] although Zahabu et al. [30] reported taller trees in widely spaced than in closely spaced teak. Since these studies investigated and reported the effect of forest stand variables to only one dimension of the tree, i.e., $H$, there is no adequate evidence on their effect on $H-D$ allometry.

Robust $H$ estimating models developed from adequate sample trees and which consider other factors that modify $H-D$ allometry are prerequisite for explaining majority of $H$ variations. Few $H$ estimating models have been developed in Tanzania Mainland but with some limitations; e.g., they covered single species [31] or utilized limited number of sample trees $[32,33]$. It is until recent where $H$ estimating models for miombo woodlands (1,392 sample trees), humid montane (751), and lowland forest (314) were developed for few selected sites [14, 28]. However, like other previously developed models, they do not incorporate climate variables. Due to heterogeneity of $H-D$ allometry associated with differences in climate and topography in Tanzania, application of these models beyond their range may not be appropriate. In addition, Tanzania has made an effort to develop accurate volume and biomass allometric equations where those utilizing $H$ in addition to $D$ have better performance in terms of mean prediction error $[4,34,35]$. These efforts will be wasted if $H$ is not accurately estimated and therefore risk tree volume and biomass estimates.

This study utilized large data set generated from the first National Forest Inventory (NFI) in Tanzania popularly known as National Forest Resources Monitoring and Assessments (NAFORMA) with the aim of developing $H$ $D$ relationship and assessing the contribution of climate and forest structure variables to the $H-D$ allometry. The developed models will mainly serve the following purposes, i.e., (1) increase precision of forest biomass and volume which utilize $H$ as predictor in addition to other variables, e.g., $D$ and wood basic density and (2) reduce forest inventory costs associated with $H$ measurements.

\section{Methodology}

2.1. Site Description. Data used in this study were obtained from a network of plots established by NAFORMA in Tanzania Mainland (Figure 1). Data were collected over the entire Tanzania Mainland covering all primary vegetation types. The country has a diverse climate with mean annual rainfall ranging from below $400 \mathrm{~mm}$ to over $2000 \mathrm{~mm}$ per annum. The rainfall for large parts of the country is bimodal with short rains from October to December and 


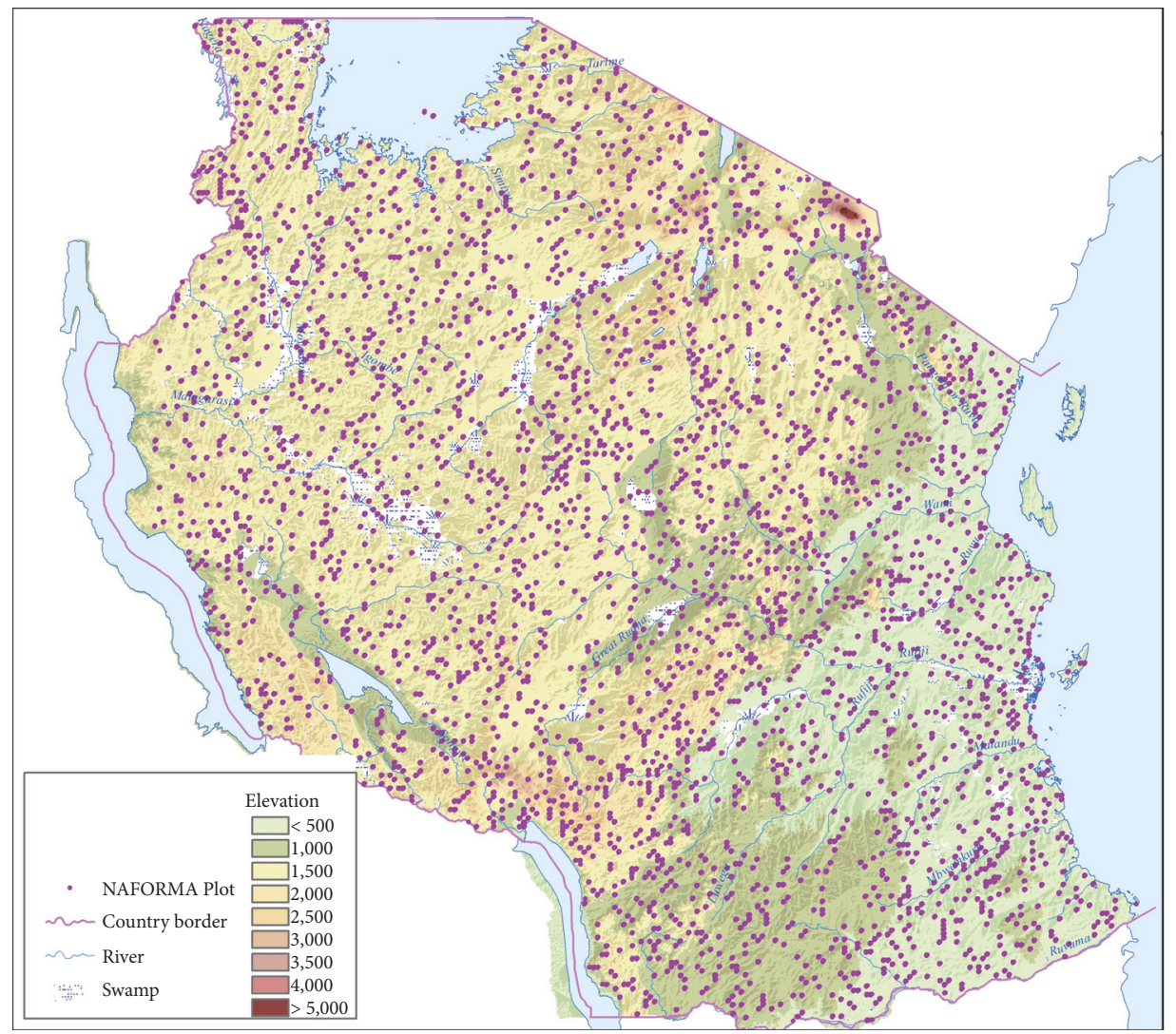

FIGURE 1: Distribution of the NAFORMA sample plots within the entire Tanzania Mainland.

long rains from March to May. The biodiversity of forests in Tanzania Mainland is high consisting over 10,000 plant species, hundreds of which are nationally endemic. Of the plant species, 305 are identified as threatened in the IUCN Red List, with 276 species classified as endangered (IUCN 2013). The main forest types include miombo woodlands, humid montane forest, lowland forest, bushland, grassland, mangroves, wetlands, cultivated areas, and plantations [36]. Some of these vegetation types are described briefly in subsequent subsections.

2.1.1. Woodlands and Bushlands. The woodlands constitute the largest vegetation type in Tanzania Mainland, occupying about 44.7 million hectares which is equivalent to $93 \%$ of the entire forest area [36]. The woodland has three subtypes: Closed ( $>40 \%$ canopy cover), Open (10-40\% canopy cover), and Woodland with scattered cropland. The height ranges between 5-20 m although occasionally being taller than 20 m.

2.1.2. Humid Montane and Lowland Forest. The humid montane and lowland forest occupy 995,000 and 1,656,500 ha, respectively, in Tanzania Mainland which is altogether about $5.5 \%$ of the countries forest area. These forests are characterized by high richness of flora and fauna and have high catchment values [43].
2.1.3. Grassland. Grassland is another vegetation type possessing marked variety, with four subtypes [44]. For the most part, this type occurs as its subtypes in combination with either a limited Wooded or Bushed component, or with scattered subsistence cultivation. The grassland subtypes are Wooded grassland, Bushed grassland, Grassland with scattered cropland, and Open grassland.

2.1.4. Cultivated Land. The cultivated land is a type of land with four vegetation subtypes [44]. The physiognomy varies widely in accordance with the significance of the tree and crop component associated with each unit. The agroforestry systems which contain permanent tree crops (timber and fruit) that are mixed with permanent and annual agricultural crops (yam, beans, banana, coffee, etc.) are recognized as one vegetation subtype. The tree crops (Grevillea, Albizia, Cordia, Citrus, Acrocarpus, etc.) which form the upper canopy act as shade to the lower canopy crops (banana, coffee, beans). The other cultivated land subtype is where the woody crops are mixed in varying proportions of fruit tree species such as mango, coconut, citrus, and cashew.

2.1.5. Mangroves. Mangroves are forests found in the tropical and subtropical coastlines between $30^{\circ}$ south and north of equator [45]. Mangroves comprise trees and shrubs which 
grow in or adjacent to the intertidal zone. They are found at primarily along sheltered shorelines where freshwater (rainfall or river flow) dilutes the ocean. At the eastern coast of Africa, 14 mangrove species are growing naturally, and 10 among these are found in Tanzania Mainland. Avicennia marina (Forssk.) Vierh, Sonneratia alba J. Smith, and Rhizophora mucronata Lam. are the three most dominant mangrove species in Tanzania [35].

2.1.6. Pine and Eucalyptus Species. Pine and Eucalyptus species are among the planted exotic tree species in Tanzania Mainland. Pine species in Tanzania Mainland include Pinus patula, $P$. elliottii, and $P$. caribaea. These species are the dominant species in most of the government and private plantations with about $78 \%$ of the total area planted and the remaining $22 \%$ is shared among hardwoods and other softwood species. In Tanzania Mainland, the area under Eucalyptus species is estimated to be 25,000 ha [46] of which 4,665 ha. The planted Eucalyptus species include E. saligna, E. grandis, E. camaldulensis, E. globulus, E. viminalis, E. citriodora, E. regnans, and E. microtheca [46].

2.2. Sampling Design and Field Measurements. Data used in this study were collected during the first ever NFI in Tanzania carried out in year between 2010 and 2014. The double sampling for stratification approach was applied. The sampling was designed based on a simulation study described by Tomppo et al. [47]. The first-phase sample consisted of clusters of plots on a $5 \times 5 \mathrm{~km}$ grid. The first-phase clusters were stratified based on predicted growing stock, time consumption for cluster measurements, and slope of the terrain. Altogether, the first-phase clusters that contain 6 to 10 plots were assigned to 18 predefined strata. The secondphase samples were systematically selected from the firstphase sample, with different sampling intensities in each of the 18 strata following an optimal allocation procedure with cost functions tailored for each stratum (see. [47]). Greater sampling intensity was allocated to strata with large predicted growing stock and smaller sampling intensity to strata with small-predicted growing stock. Only the clusters selected during the second phase of sampling were measured in the field. The distance between field plots within a cluster was $250 \mathrm{~m}$, while the distance between clusters varies from $5 \mathrm{~km}$ to $45 \mathrm{~km}$. For each cluster plots spaced $250 \mathrm{~m}$ apart varied from 6 to 10 depending on estimated difficulty to access the cluster (Figure 2). Accordingly, a total of 3,420 clusters with 32,660 plots were adopted. However, during the fieldwork, a total of 3,219 clusters which are equivalent to 30,773 plots were actually measured. Some clusters were not measured for various reasons, mainly difficult terrain and remoteness. Circular fixed area nested plot designs were applied. The nested plots included $1,5,10$, and $15 \mathrm{~m}$ radius concentric plots.

Measurements of $D$ for all the trees within the plot were in accordance with the tree size and distance from plot centre where larger trees where measured in larger plot and vice versa [47]. For all the trees measured in the plot, species names were recorded both botanical and local names. Every fifth tree in the cluster was selected as sample tree

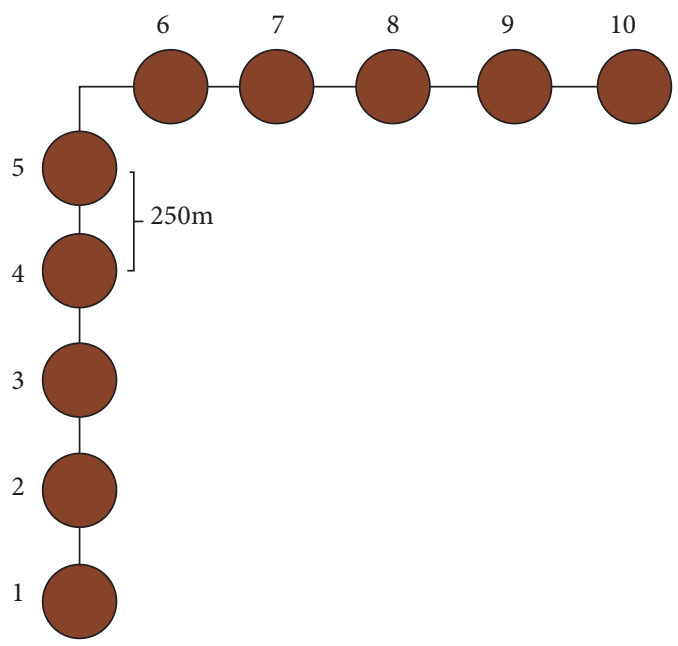

Figure 2: The NAFORMA cluster and plot design [36].

and measured for $H$ using Suunto hypsometers. We refer the readers to MNRT [36] for more details on the field measurements.

2.3. Data Preparation. Following data cleaning to remove outliers in the NAFORMA data, a total of 31782 observations were obtained for analysis. During preliminary data analysis scatterplots revealed relationships between $H$ and $D$ varying with vegetation types. Accordingly, for modelling purpose, the entire data were grouped into vegetation types in order to account for variations in $H-D$ allometry that might be attributed by the tree allometry associated with the specific vegetation type. The relationship between response and predictor variables was assessed by means of scatter plots. The $H-D$ plots indicated nonlinear relationship (Figure 3). Summary statistics for variable under consideration for each forest type is presented in Table 1.

2.3.1. Climate Data and Forest Stand Parameters. Climate data of $2.5 \mathrm{~min}$ resolution were downloaded from http://worldclim.org/version2 covering a period between 1970 and 2000 [48]. Climate data parameters of interest were mean annual precipitation $\left(P R_{A}\right)$, number of months with precipitation below $100 \mathrm{~mm}\left(d_{m}\right)$ and mean annual temperature $\left(T E_{A}\right)$. Candidate stand forest parameter variables tested were stand level competition variables, i.e., basal area $\left(B A, \mathrm{~m}^{2}\right.$ $\mathrm{ha}^{-1}$ ), a distance-independent tree-level competition index ( $C I$, a ratio of $D$ to the plot-level quadratic mean diameter (e.g., [49]). Summary statistics of climate and stand forest variables are shown in Table 1.

\subsection{Modelling}

2.4.1. Height Estimating Base Models. Several models describing $H-D$ relationships have been reported in the past $[2,19$, 28]. No uniformly best function has been recommended, suggesting that $H-D$ allometry differs significantly among forests (e.g., [21, 50]). We first developed $H$ estimating models 


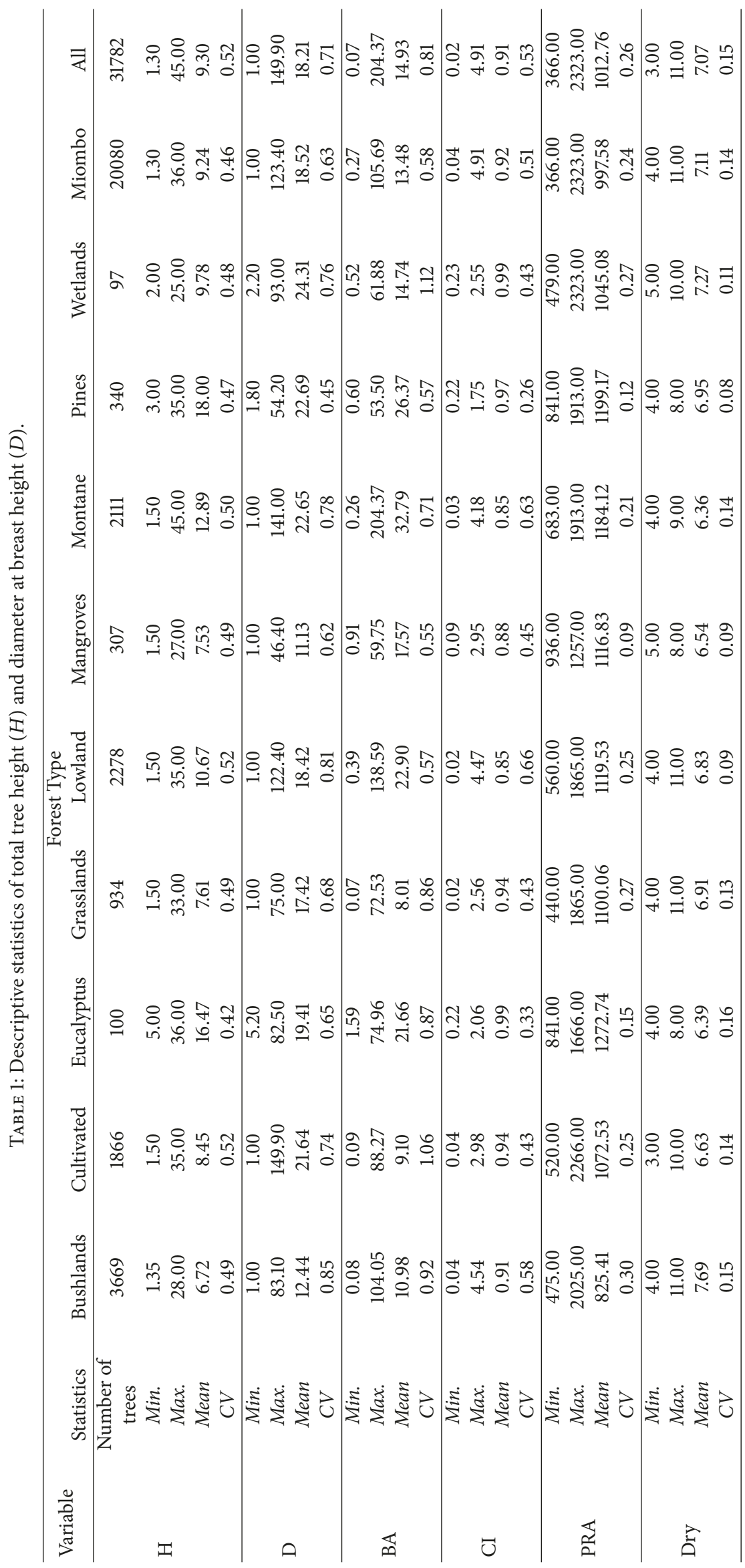




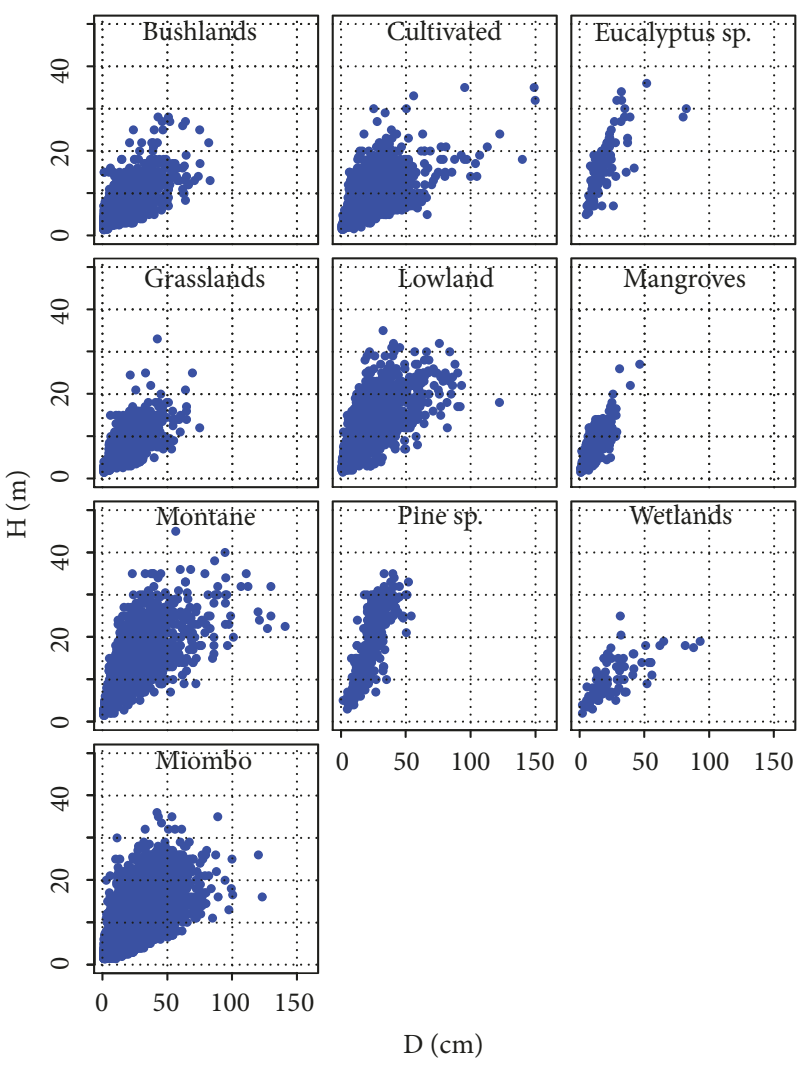

Figure 3: Scatter plots of $H-D$ allometry.

which had only $D$ as sole explanatory variable herein referred as "base model". This was necessary so as to make comparison of base models with other $H$ estimating models which include climate and forest stand variables herein referred as "generalized models". In addition, $H$ base models are required for estimating $H$ when forest structure and climate variables are not available. Furthermore, we fitted $H$ estimating models to all data set combined herein referred as "regional models". We fitted six common $H$ estimating model forms, i.e., three with two parameters and other three with three parameters (Table 2).

2.4.2. Generalized Tree Height Models. For complex models with several independent variables, i.e., forest structure and climate variables (generalized model), simple log-log model has been preferred partly because it is easy to converge when estimating model parameters [2]. Limitation associated with log-log model include problem of back transformation and lack of flexibility to set maximum $H$ a tree must not exceed $[21,50]$. It is through this background that in this study we decided to fit nonlinear models which agree with known biological $H$-D allometry. We included climate and forest structure variables into six nonlinear $H$ model forms (Table 2) and refitted the models. It was apparent that majority of the fitted model forms failed to converge. Weibull model was the most successful in terms of convergence and fit and therefore was selected to fit generalized $H$ models (see [51]). The formulation of three parameters Weibull model is presented in equation (1)

$$
H=1.3+\alpha\left(1-\exp \left(-\beta_{1} D^{\beta_{2}}\right)\right)+\epsilon
$$

where $\alpha, \beta_{1}$, and $\beta_{2}$ are model parameters to be estimated and $\epsilon$ is unexplained variation in $H$. Parameter $\alpha$ describes the maximum $H$ the model can predict; $\beta_{1}$ describes the rate of change of $H$ with change in $D$ and $\beta_{2}$ describes the shape of the curve.

The NAFORMA data represent a hierarchical structure where the field plots were nested within the clusters. In this case, nonlinear mixed effect modelling approach was considered to be an ideal for developing predictive models that will account for dependence of the plots within the clusters. In addition, to account for variation (i.e., heteroscedasticity due to cluster and $D$ ) not accounted by the random effects, we also included power variance function structure, i.e., varPower, implemented in the nlme packages of R software for nonlinear and linear models [52]. Preliminary model fitting showed that model with plots nested in cluster was not able to converge probably due to few observations [21] in some vegetation types. Model with only cluster as random variable converged successful. Therefore, the fixed effects (equation (1)) are common to all subjects, while random effect parameters are specific to each subject (in this case cluster) [52], (Zuur et al. 2009). At the beginning, we allowed all model parameters to vary between clusters through inclusion of random effects. The model fitted data well by only allowing random effect on parameter $\beta_{2}$. With the inclusion of random effects, the following equation (2) emerged:

$$
H=\alpha\left(1-\exp \left(-\beta_{1} D^{\beta_{2}+R_{i}}\right)\right)+\epsilon
$$

where $R_{i}$ expresses the difference in parameter $\beta_{2}$ of cluster $i$ from mean value obtained from (1) or typical cluster.

The next step was to ascertain the effect of forest structure and climate parameters on $H-D$ allometry. We refer this model as "generalized model". Before fitting generalized $H$ estimation models, we explored relationship of climate and forest structure variables with $H$ in each vegetation type. Preliminary results show that at least one of the dependent variables $\left(B A, C I, P R A\right.$, and $\left.d_{m}\right)$ is highly correlated with $H$ of the studied forest types (Figure 4). We consider forest structure and climate variables to mostly affect asymptotic parameter, i.e., $\alpha$. The parameter $\alpha$ was further expanded as shown in (3). The generalized model variables, i.e., $P R A, C I$, $d_{m}$ and BA were allowed to enter into the model linearly for easy evaluation of their contribution (equation (3)).

$$
\alpha=\theta_{0}+\theta_{1} P R_{A}+\theta_{2} C I+\theta_{3} d_{m}+\theta_{4} B A
$$

where $\theta^{\prime} s$ are model parameters.

2.5. Model Fitting and Performance Evaluation. Heightdiameter models were fitted by considering the contribution of the random effect associated with clusters. In addition, to account for variation (i.e., heteroscedasticity due to clusters and $D$ ) not accounted by the random effects, we included 

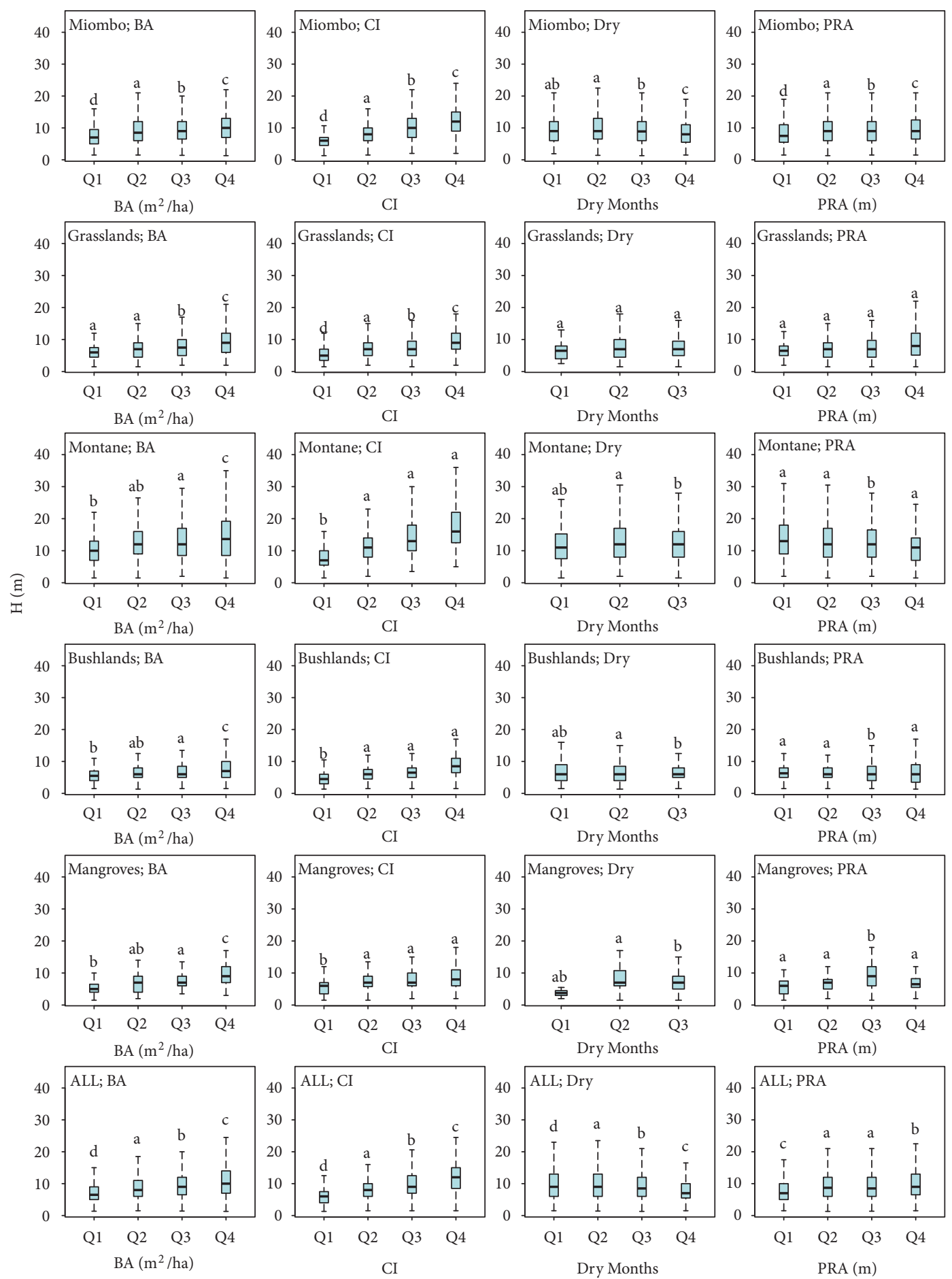

FIGURE 4: The relationship of total tree height $(H)$ with forest stand $(B A, C I)$ and climatic variables (number of dry month and precipitation). Different letters indicate significant differences among groups. Q1, Q2, Q3, and Q4 are quantiles.

power variance function, i.e., varPower, implemented in the nlme packages of $\mathrm{R}$ software for nonlinear regression equations $[52,53]$. The models were fitted using Maximum Likelihood procedure. To ensure that our modelling strategy has accounted for heteroscedasticity, models were assessed using residuals plots. We assessed the contribution of forest stand and climate variables by looking at the significance of their respective parameters. Variables with nonsignificant parameter were considered irrelevant to $H-D$ allometry.

To present generalized $H$ estimation models for practical application, we selected those with low Akaike Information Criterion (AIC) and evaluated the best first three models. 
TABLE 2: Height base model forms.

\begin{tabular}{llr}
\hline Model \# & Model form & Reference \\
\hline 1 & $H=1.3+\left(D^{2} /\left(\emptyset_{0} \times D+\emptyset_{1}\right)^{2}\right)$ & {$[37]$} \\
2 & $H=1.3+\exp \left(\emptyset_{0}-\emptyset_{1} \times(D+1)^{-1}\right)$ & {$[38]$} \\
3 & $H=1.3+\emptyset_{0} \times(D /(1+D))^{\emptyset_{1}}$ & {$[18,39]$} \\
4 & $H=1.3+\emptyset_{0} \times\left(1-\exp \left(-\emptyset_{1} \times D\right)\right)^{\emptyset_{2}}$ & {$[40]$} \\
5 & $H=1.3+\emptyset_{0} \times \exp \left(\emptyset_{1} /\left(D+\emptyset_{2}\right)\right)$ & {$[41]$} \\
6 & $H=1.3+\emptyset_{0} \times\left(1-\exp \left(-\emptyset_{1} \times D^{\emptyset_{2}}\right)\right)$ & {$[42]$} \\
\hline
\end{tabular}

$\emptyset$ 's are parameters to be estimated.

TABLE 3: Parameters estimates and performance of height base models.

\begin{tabular}{|c|c|c|c|c|c|c|c|c|c|c|c|c|}
\hline Forest & Model & SE \% & AIC & Forest & SE \% & AIC & Forest & SE $\%$ & AIC & Forest & SE \% & AIC \\
\hline \multirow{6}{*}{$\mathrm{BU}$} & 1 & 34.8 & 15752 & \multirow{6}{*}{ CUL } & 40.7 & 9408 & \multirow{6}{*}{ EUC } & 25.5 & 561 & \multirow{6}{*}{ GRA } & 36.0 & 4311 \\
\hline & 2 & 35.5 & 15783 & & 41.2 & 9439 & & 25.7 & 563 & & 36.4 & 4331 \\
\hline & 3 & 36.1 & 15915 & & 41.3 & 9464 & & 25.9 & 563 & & 36.5 & 4344 \\
\hline & 4 & 32.4 & 15430 & & 40.3 & 9388 & & 25.4 & 564 & & 35.6 & 4290 \\
\hline & 5 & 33.0 & 15510 & & 40.4 & 9389 & & 25.5 & 563 & & 35.7 & 4288 \\
\hline & 6 & 32.4 & 15428 & & 40.2 & 9386 & & 25.4 & 564 & & 35.5 & 4290 \\
\hline \multirow{6}{*}{ LO } & 1 & 34.9 & 11893 & \multirow{6}{*}{ MAN } & 28.5 & 1316 & \multirow{6}{*}{ HUM } & 34.3 & 11779 & \multirow{6}{*}{ ALL } & 42.7 & 156220 \\
\hline & 2 & 36.1 & 11987 & & 28.8 & 1320 & & 35.2 & 11862 & & 36.3 & 157410 \\
\hline & 3 & 36.2 & 12069 & & 29.1 & 1326 & & 35.3 & 11906 & & 36.5 & 158053 \\
\hline & 4 & 33.7 & 11703 & & 27.9 & 1312 & & 33.5 & 11685 & & 34.5 & 154230 \\
\hline & 5 & 33.8 & 11721 & & 28.1 & 1314 & & 33.6 & 11706 & & 34.6 & 154460 \\
\hline & 6 & 33.7 & 11703 & & 27.8 & 1311 & & 33.5 & 11684 & & 34.5 & 154229 \\
\hline \multirow{6}{*}{ WET } & 1 & 31.6 & 486 & \multirow{6}{*}{ MIO } & 31.2 & 96575 & \multirow{6}{*}{ PIN } & 26.5 & 2007 & & & \\
\hline & 2 & 31.9 & 490 & & 31.8 & 97303 & & 26.2 & 2008 & & & \\
\hline & 3 & 32.1 & 491 & & 31.9 & 97616 & & 26.2 & 2009 & & & \\
\hline & 4 & 31.7 & 486 & & 30.7 & 95686 & & 26.1 & 2003 & & & \\
\hline & 5 & 31.6 & 485 & & 30.7 & 95757 & & 26.3 & 2007 & & & \\
\hline & 6 & 31.7 & 486 & & 30.7 & 95683 & & 26.0 & 2001 & & & \\
\hline
\end{tabular}

BU: Bushlands; LO: Lowland; WET: Wetlands; CU: Cultivated land; MAN: Mangroves; EUC: Eucalyptus species; HUM: Humid montane; GRA: Grasslands; and PIN: Pines species.

Percentage Root Mean Square Error (SE\%) was also assessed. We also assessed the models by means of residuals plots where models with more balanced residuals were selected.

In addition, preliminary findings (Figures 3 and 4) show that climate variables specifically $P R_{A}$ varies among forest types which consequently may affect $H-D$ allometry. Variation of $H$ among forest types of Tanzania Mainland has been reported also by other scholars $[27,54]$. Therefore, assuming that the variation in $P R_{A}$ within the same forest type may not necessarily influence $H-D$ allometry significantly, it is expected that other factors such as competition expressed in terms of $C I$ and $B A$ may have the role of modifying $H-D$ allometry. With large data set, collected from NAFORMA, it is expected that large variation associated with species, site condition, and stand structure difference has been adequately covered. Since the regional models have some of these potential variables, we therefore tested mean prediction error $(P E \%)$ of the regional models with and without climate and/or stand forest variables to ascertain which one may adequately predict $H$ of all forest types. The mean prediction error was calculated using the following equation:

$$
P E \%=\sum\left[\frac{(\widehat{H}-H) / H}{n}\right] \times 100
$$

where $\widehat{H}$ and $H$ are predicted and observed total tree height, respectively and $n$ is the number of sample trees.

\section{Results}

3.1. Height Base Model. Performance of base models is shown in Table 3. The SE\% were found to range from $25.4 \%$ to $41.3 \%$ across forest types. Forests with highest SE\% were found to be bushlands followed by lowland and montane forests. Forests with low SE\% were pines (26.5\%) and Eucalyptus $(25.5 \%)$ plantations and mangroves forest (28.1\%) for natural forests. In terms of performance, based on AIC, Model (6) had a good fit in all forest types except for wetland forests. Model (1) was the second in performance. Model (1), i.e., Ratkowsky [41], was selected for wetland forests while for other forests Model (6), Weibull [42], was selected. Parameter estimates and mode expressions are provided in Table 4. 
TABLE 4: Best selected height base models.

\begin{tabular}{lcc}
\hline Model & Forest type & Model expression \\
\hline Weibull [42] & Bushlands & $1.3+37.0396 \times\left(1-\exp \left(-0.03778 \times D^{0.6063}\right)\right)$ \\
Weibull [42] & Cultivated land & $1.3+13.6509 \times\left(1-\exp \left(-0.06223 \times D^{0.8600}\right)\right)$ \\
Weibull [42] & Eucalyptus species & $1.3+29.3684 \times\left(1-\exp \left(-0.03148 \times D^{1.1061}\right)\right)$ \\
Weibull [42] & Grasslands & $1.3+14.7261 \times\left(1-\exp \left(-0.0536 \times D^{0.8637}\right)\right)$ \\
Weibull [42] & Lowland & $1.3+24.9862 \times\left(1-\exp \left(-0.0579 \times D^{0.7682}\right)\right)$ \\
Weibull [42] & Mangroves & $1.3+15.8607 \times\left(1-\exp \left(-0.0705 \times D^{0.8520}\right)\right)$ \\
Weibull [42] & Humid montane & $1.3+25.6752 \times\left(1-\exp \left(-0.0536 \times D^{0.8234}\right)\right.$ \\
Weibull [42] & Pine species & $1.3+28.5979 \times\left(1-\exp \left(-0.0064 \times D^{1.6174}\right)\right)$ \\
Ratkowsky [41] & Wetlands & $1.3+20.4098 \times \exp (-23.1909 /(D+6.7727))$ \\
Weibull [42] & Woodlands & $1.3+24.3701 \times\left(1-\exp \left(-0.0405 \times D^{0.8070}\right)\right)$ \\
Weibull [42] & Reginal & $1.3+30.2116 \times\left(1-\exp \left(-0.0379 \times D^{0.7451}\right)\right)$ \\
\hline
\end{tabular}

\subsection{Height Estimating Models with Climate and Forest Stand Variables}

3.2.1. Regional Generalized Height Models. The findings show that all parameters of the fitted regional models were significant; i.e., all fitted variables had significant contribution in explaining $H$ (Table 5). The magnitude of importance of independent variables decreased in the following order, $B A, P R_{A}, d_{m}$, and CI. Based on AIC, the model which combines all the independent variables was found to have best fit. Positive parameters for $P R_{A}$ and $B A$ suggest that as precipitation and stand density increases, the mean $H$ also increases (e.g., Figure 5). Trend of mean $P R_{A}$ versus mean $H$ is shown in Figure 4.

3.2.2. Generalized Height Models for Lowland and Montane. For both forest types, all parameters estimates were significant when forest structure and climate variables were included in the model one by one except for $d_{m}$ in the montane forest (Table 5). The magnitude of importance of independent variables for lowland and montane forests decreased in the following order: $B A>P R_{A}>C I$ and $B A>C I>P R_{A}>$ $d_{m}$, respectively. In many cases combinations which include $\mathrm{CI}, \mathrm{CI}$ were found to be nonsignificant. For example, for lowland, a model with a combination of $B A$ and $C I$ and $P R_{A}$ and $C I$ consistently yielded nonsignificant parameters for $C I$. For the lowland, the five best models in decreasing order of model fit had the following combination of variables, i.e., $B A, d_{m}$, $P R_{A}>B A, P R_{A}>d_{m}, P R A>B A, d_{m}>B A$ while for the montane they were $B A, C I>B A, P R_{A}>B A>C I, P R_{A}>C I$.

3.2.3. Generalized Height Models for Miombo Woodlands. All variable combinations yielded significant model parameters. Model with all variables had the best fit. The importance of stand and climate variables decreased in following order: $B A$ $>P R_{A}>C I>d_{m}$. The models fit decreased in the following order of combination: BA, CI, $d_{m}, P R_{A}>B A, C I, P R_{A}>B A$, $d_{m}, P R_{A}>B A, P R_{A}>B A, C I, d_{m}$.

3.2.4. Generalized Height Models for Mangroves and Wetlands. Climate variables were not found to influence $H-D$ allometry in both wetlands and mangroves forests. Except for mangroves where $B A$ was a significant variable, forest stands variables did not improve the $H$ estimating model fit in wetlands. This implies that $H$ base models were found to describe $H-D$ allometry adequately for wetland forests (Table 5). In mangroves, model with BA included had better fit than base model.

3.2.5. Generalized Height Models for Bushland, Cultivated, and Grasslands. The PRA in combination with $d_{m}$ and/or CI did not improve model fit for bushlands. Important variables in decreasing order were $B A, d_{m}$, and $P R_{A}$. In cultivated lands, $B A, d_{m}$, and $P R_{A}$ were found to be important in that order in describing $H-D$ allometry while $C I$ was found to be nonsignificant. In grasslands, $C I$ and $d_{m}$ did not add value to the model while BA was the most significant variable followed by $P R_{A}$. The combination with good fit in decreasing order in the bushlands was found to be $B A, \mathrm{CI}, d_{m}>B A, P R_{A}>B A$, $d_{m}>\mathrm{BA}$, for the grassland, $B A, d_{m}, P R_{A}>B A, P R_{A}>B A>$ $d_{m}, P R_{A}>P R_{A}$, and for cultivated lands, $\mathrm{BA}, d_{m}>B A>\mathrm{CI}$, $d_{m}$.

3.2.6. Generalized Height Models for Pines and Eucalyptus Species. The most important variables describing variation in $H$ were found to be forest stand variables, i.e., $B A$ and $C I$ for both plantation tree species of Eucalyptus and pines. Climate variables, i.e., $P R_{A}$ and $d_{m}$, were found to be nonsignificant. When $P R_{A}$ or $d_{m}$ are combined with $B A$, the climate variables were found to be important in describing $H-D$ allometry for Eucalyptus species.

3.3. Application of the Developed Models. Although $H$ estimating models with climate and forest structure variables proved to be superior, except for wetlands forest (failure to converge), $H$ base models for all forest types are also presented for practical reasons, i.e., to be applied when climate and forest stand variables are not available (Table 4; e.g., $[14,28])$. Of the fitted generalized $H$ estimating models (Table 5), we selected at least two best models for each forest type and regional models for further evaluation except for mangrove forest (one model selected) and wetlands (none 


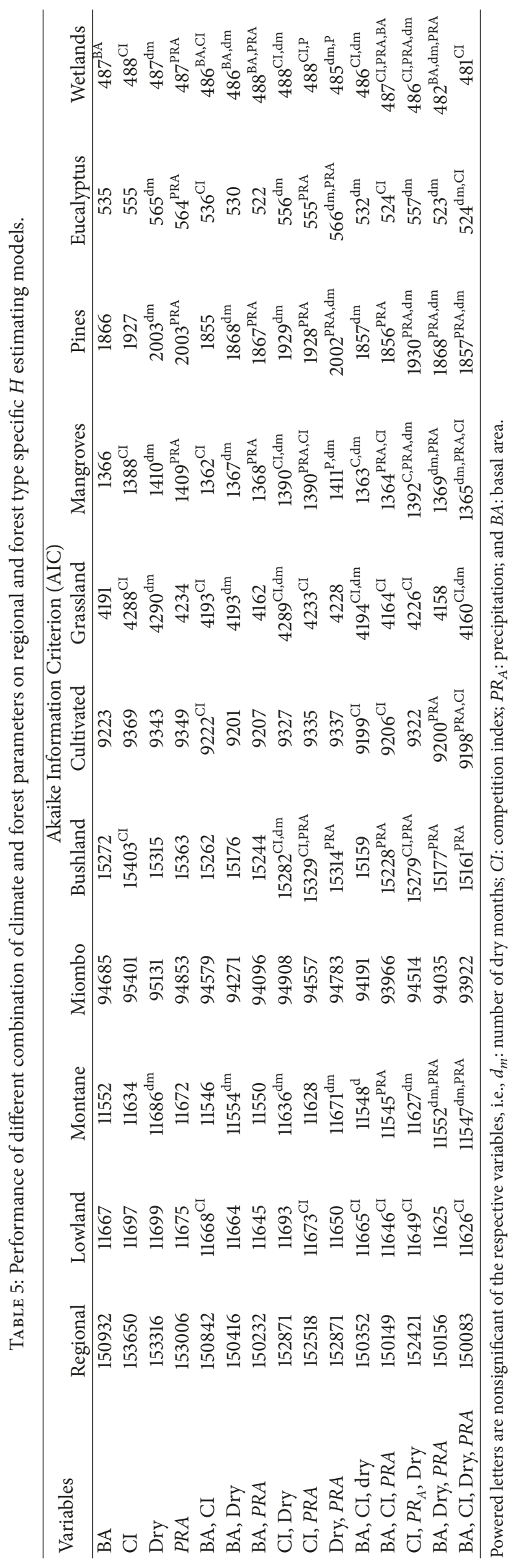



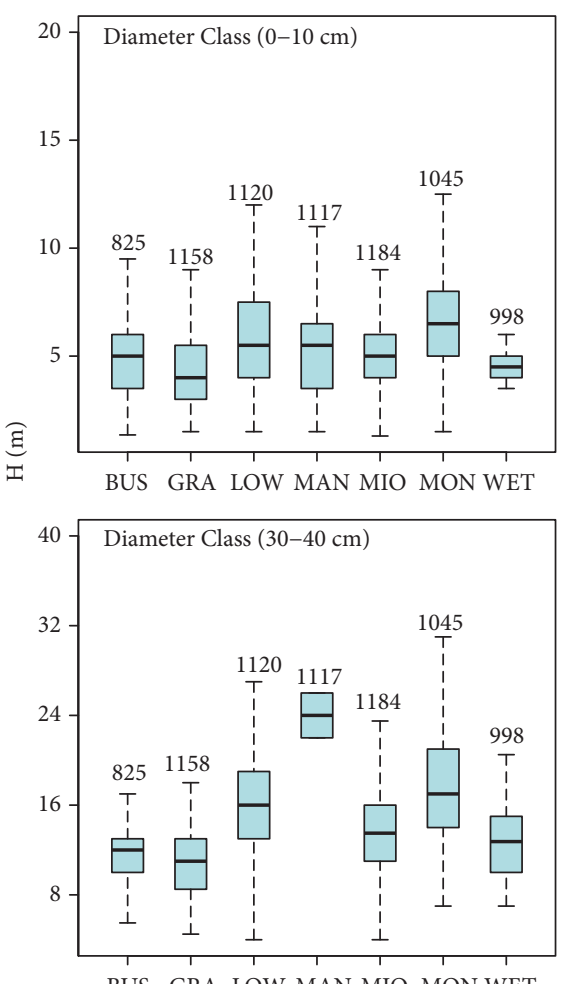

BUS GRA LOW MAN MIO MON WET

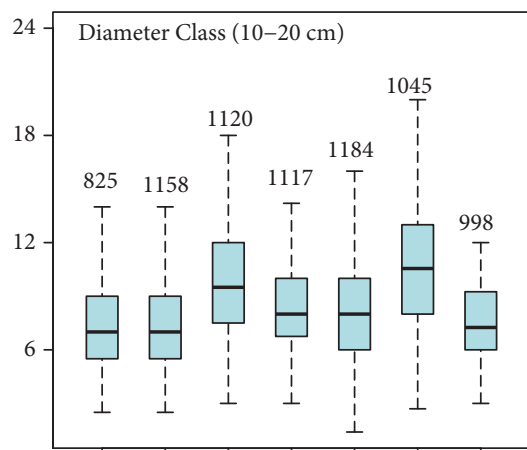

BUS GRA LOW MAN MIO MON WET

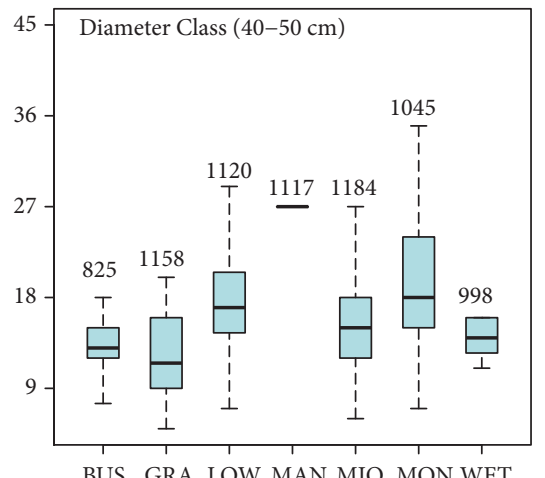

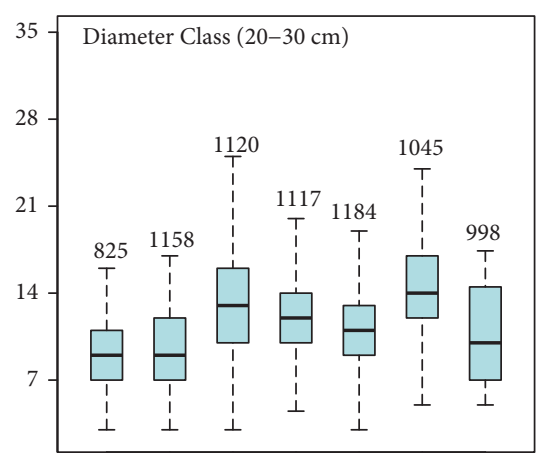

BUS GRA LOW MAN MIO MON WET

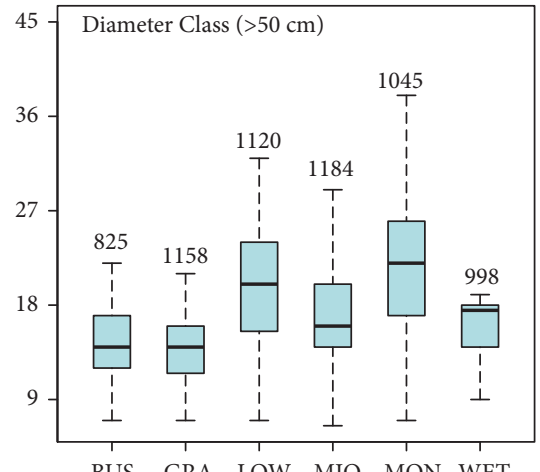

FIGURE 5: Effect of precipitation to total tree height distributed in diameter classes. $P R_{A}$ values above the box are in mm. BUS: Bushland; GRA: Grassland; LOW: Lowland; MAN: Mangroves; MIO: Miombo; MON: Montane; and WET: Wetlands.

was selected). We prioritize and select simple and practical models instead of complex models with large number of variables.

The selected models were refitted by allowing stand and climate variables to enter into the model nonlinearly. This is because $H$ increases to asymptote with the increase of climate and stand variables. However, not all the models were able to converge, e.g., bushlands, grasslands, mangroves, and Eucalyptus species, while also for some, we maintained variables getting into the model linearly due to poor model fit. Models in which climate or forest stand variables were not significant are not presented in Table 6. It was evident that $B A$ was an important variable for every vegetation except wetlands. Addition of $P R_{A}$ improved model fit for reginal model, lowland, miombo, and grassland forests (Table 6). The $C I$ improved model fit for montane, miombo, bushland, and pine forests. The $P R_{A}$, however, was not important to wetlands, mangroves, montane forest, and pine species when BA enters into the model nonlinearly. The number of dry month $\left(d_{m}\right)$ improved the model fit for only cultivated land and bushlands.

At this end, the best regional models were found to be that which consist of sole $B A$ and a combination of $B A$ and $P R_{A}$. Base model had the poorest performance. The residual box plot and mean prediction error ( $P E \%)$ for the three regional models are shown in Figure 6 and Table 7, respectively. The performance of the model with sole $B A$ and that of $B A$ and $P R_{A}$ when evaluated against forest types did not differ significantly. The prediction error ranged between $-1.26 \%$ and
$-21.68 \%$. The two models produced relatively lower prediction error to the bushlands, lowlands, mangroves, montane, and miombo woodlands. The two models consistently produced similar pattern of residuals; i.e., both were biased to wetlands and grassland trees (Figure 6). The PE\% for the basic model were found to be relatively high to all forest types except for lowland and mangrove forests (Table 7). This was also evident when evaluating the model by means of residuals (Figure 6).

\section{Discussion}

4.1. Height Base Models. This study aimed at developing $H$ estimating models for different forest types in Tanzania Mainland using the National Forest Inventory data collected through NAFORMA program. We also assessed how climate and forest stand variables modify $H-D$ allometry. This is the first study with $H$ estimating models developed from sample trees covering the entire country of Tanzania. As such the models developed from this study are robust enough to account for different tree allometry variations which might be attributed by differences in forest types as well as climatic conditions. Several $H$ estimating model forms were tested and evaluated but generally Weibull model turned out to be the best and was able to smoothly converge when climate and forest stand variables are included (Tables 5 and 6). In addition, the fact that the model form has asymptotic characteristics complies with biological features of $H$ growth. This characteristic may explain why Weibull model has been reported to be more appropriate for prediction of above 


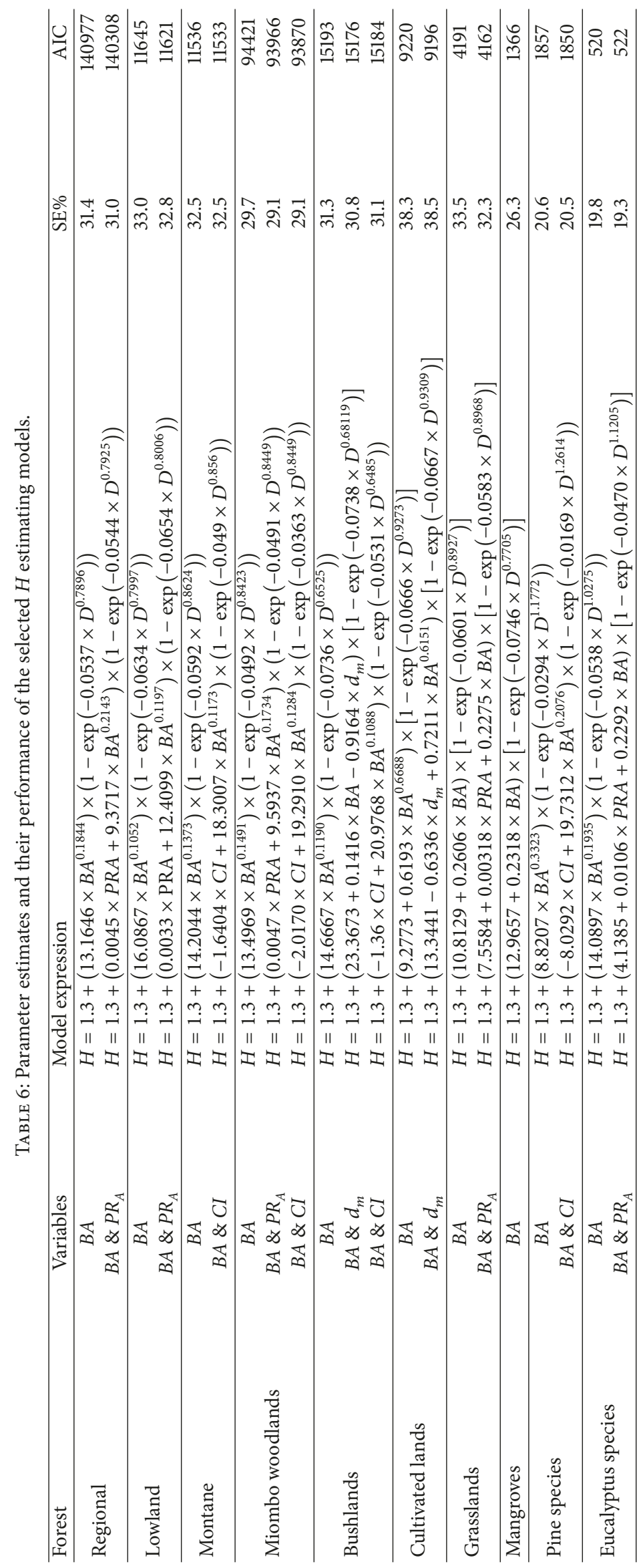




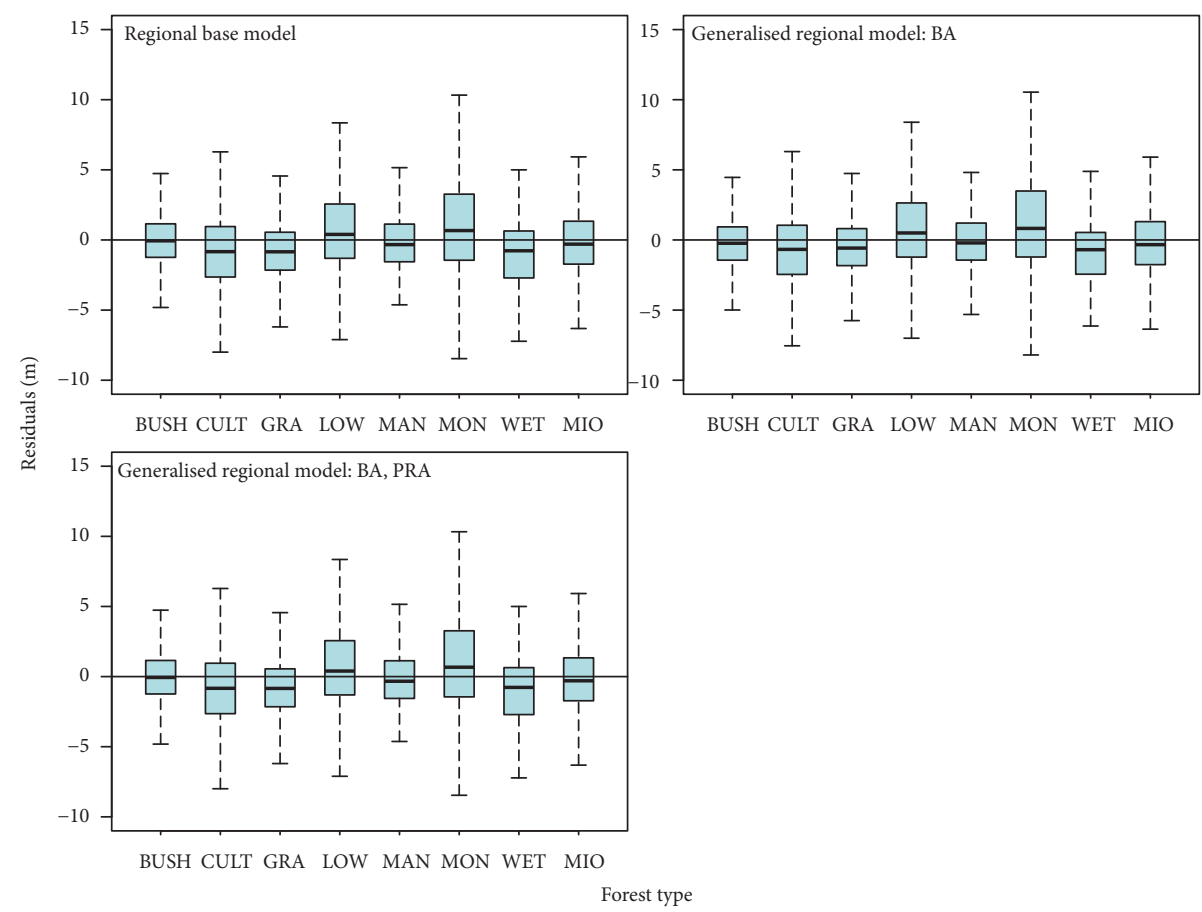

FIGURE 6: Evaluation of regional models to the studied from types BUS: Bushland; GRA: Grassland; LOW: Lowland; MAN: Mangroves; MIO: Miombo; MON: Montane; and WET: Wetlands.

TABLE 7: Prediction error of the fitted base and generalized regional models to the studied forest types.

\begin{tabular}{lccc}
\hline \multirow{2}{*}{ Forest Type } & \multicolumn{3}{c}{ Prediction error (\%) } \\
& $D$ & $D \& B A$ & $D, B A \& P R_{A}$ \\
\hline Bushlands & -18.41 & -11.32 & -8.09 \\
Grasslands & -32.48 & -16.83 & -21.68 \\
Lowlands & 4.49 & -1.88 & -3.10 \\
Mangroves & -6.17 & -9.50 & -11.29 \\
Montane & 10.78 & 0.82 & -1.26 \\
Wetlands & -20.12 & -13.51 & -14.67 \\
Woodlands & -12.79 & -11.06 & -10.72 \\
\hline
\end{tabular}

ground biomass and reduces errors for trees of extreme $D$ compared to nonasymptote which tend to overestimate biomass of extreme trees [50]. With such a big data set used in this study where the confidence that most of $H-D$ variation has been captured is high, e.g., good presentation of trees which have reached maximum $H$ growth, the asymptotic Weibull model may be more appropriate than the log-log model.

The Weibull model was found to be superior in all forest types except in wetland. The performance of Weibull models has been widely reported and used to describe tree allometric relationships, especially $H-D$ relationships reported by other scholars [19, 50, 55-57]. The SE\% for the base model was found to be relatively higher than that of generalized models (Tables 3 and 6). This may be explained by large variations in $H$ which could not be explained by $D$ alone. However, the error margin corresponds to the reported findings elsewhere
[19, 28, 57]. Mangroves and plantation tree species, i.e., pine and Eucalyptus, had relatively lower SE\% compared to other forest types. Mangroves have rather fewer woody tree species [35] which may translate to low $H$ variation. This also applies to pines and Eucalyptus trees species which have more uniform allometry in plantation.

4.2. Height-Diameter Allometry and Climate. The findings show mean $H$ of all forest types which were affected by $P R_{A}$ and $d_{m}$ in a regular pattern (Figure 2) and show high coefficient of variation of both $P R_{A}$ and $d_{m}$ (Table 1); $P R_{A}$ and $d_{m}$ were also found to affect the $H-D$ allometry significantly. The affected forest types include all data combined, bushlands, cultivated land, grasslands, miombo woodlands, and lowlands (Table 1). The observed trend may be explained by the fact that the reported forest types are widely distributed in the country and therefore exposed to different $P R_{A}$ and $d_{m}$ patterns (Table 1; [36]). Taking an example of lowland forests, where two subclasses exist, i.e., semideciduous normally found inland receiving relative low rainfall compared to evergreen forests in the coastal regions [58] with more or less comparable tree species composition, it was found that trees in coastal regions were taller than those found inland [10]. Phenotypic plasticity of trees responses to climate and other environmental conditions such as altitude and soil characteristics may explain these differences [59]. This pattern is also supported by Vizcaíno-Palomar et al. [13] who studied the effect of climate and population origin to the $H-D$ allometry and found that some species modify $H$ - $D$ allometry (e.g., Pinus halepensis and Pinus pinaster) when growing in environment with varying $P R_{A}$ while others maintain the 
$H$-D allometry (e.g., Pinus sylvestris and P. nigra). However, pines and Eucalyptus species were not affected by $P R_{A}$ and $d_{m}$. Dominant pine species grown in Tanzania Mainland at large scale is Pinus patula in southern and northern highlands [60]. These areas experience similar climatic conditions which may explain why this study did not find $H-D$ allometry variation associated with $P R_{A}$. On the other hand, Eucalyptus species is widely distributed in both dry and wet areas where we would expect to find the effect of $P R_{A}$ and $d_{m}$ on their $H-D$ allometry. However, the effect of $P R_{A}$ and $d_{m}$ were insignificant suggesting inconsistent $H$-D allometry response to climatic condition $[61,62]$.

Furthermore, when comparing mean $H$ of forest types, the findings show that mean $H$ increases with the increase of $P R_{A}$ (Figure 5) and decreases with the increase of $d_{m}$ with few exceptions, i.e., grasslands (Figure 4). Generally, these findings are in line with those reported by Burgess et al. [27] who found that maximum $H$ decreases with decreasing $P R_{A}$ in this order, i.e., montane, lowland, closed woodlands, and open woodlands. The contradicting results with grassland maybe due to the fact that the vegetation type is mainly found in the southern highlands which experience high $P R_{A}$ and also in patches woodlands with moderate $P R_{A}$. In the grasslands trees are normally scattered and therefore it is likely that they are not struggling for light resource for vertical growth and therefore invest more on branches (horizontal growth; [63, 64]). This is further justified by nonsignificant parameter for $C I$ as shown in Table 5 since the trees experience no competition. On the other hand, although wetlands and mangroves forests receive moderate $P R_{A}$, it was expected that trees would be taller than those found in other forests since these areas are wetter throughout the year. This implies that there are other factors other than PRA such as genetics, soils fertility and depth, winds, and humidity which also modify $H-D$ allometry which were not captured in our data set $[2,59]$. Trend observed in this study provides vital information on tree allometry response to climatic condition. Climate fluctuations are even more urgent because climate changes are expected to cause stronger climatic variability, with increased frequency of extreme dry years which will affect distribution, allometry of tree species and consequently forest biomass [65-68].

\subsection{Height-Diameter Allometry and Forest Structure Vari-} ables. The findings from this study show that BA in most cases (except for wetlands forests) have a strong influence on $H-D$ allometry, i.e., increasing of $H$ with increasing BA. This pattern suggests that $H$ - $D$ allometry varies within forest type, i.e., among plots. This implies that when excluding BA as a predictor, different $H-D$ equation would be required for each plot [69]. There are contradicting findings reported on the effect of stand density to $H$ (e.g., [70]). Other scholars have claimed that the vertical and horizontal dimensional change of a tree is linked with the availability of resources: solar radiation, water, and nutrients. Consequently, site quality has been conventionally determined by dominant $H$ which is considered to be less sensitive to stand density such as $B A$ [71]. Dunning [72] and Baker [73] have shown that $H$ may be affected by stand density. However, the inconsistence of the reported findings has been shown to be attributed by size of plots and variable responses of different tree species to stand density [70]. Data collected in larger plots have shown to be more explanatory to this phenomenon than those collected in small plots [70]. Due to the consistence of our findings, we rule out that the plot size applied in this study was adequate to explain $H$-stand density relationships. In addition, while few tree species are shade tolerant, light demanders in a tightly packed setup may be forced to shoot upward in pursuit of sunlight $[74,75]$. On the other hand, trees growing in a densely packed stems are not susceptible to wind damage due to sheltering effect and therefore they are likely to invest in $H$ than $D$ since mechanical support may not be the priority $[2,76]$.

While increase in $B A$ aggravates competition for resources and affects tree growth, the magnitude of the impact may be experienced differently from one tree to another depending on their sizes [77, 78]. This is when the tree status in terms of $C I$ becomes important, thus explaining how a tree is affected by neighboring trees. It is expected that tree with large $C I$ to have "proportionally" large $H$, i.e., larger trees have more advantages in resources capturing than the small trees [22]. However, this interaction favors $D$ growth rather than $H$. For example, Mugasha et al. [79] reported diameter increment to be positively linked to $C I$. This imply that while small trees have narrow ground for resources since adjacently they are outmatched with larger trees [80], they capitalize on $H$ growth in pursuit for sunlight [75]. Therefore, it is not surprising that in this study CI was inversely proportional to $H$ in all forest types except for wetland where $C I$ was not significant but maintained similar trend. Insignificant $C I$ parameter for wetland forest may be associated with the limited number of observations used in modelling, i.e., 97 observations (Table 1).

4.4. Application of Height-Diameter Models. Prediction of $H$ is critical step when estimating other forest parameters such as forest biomass and volume (e.g., [1]). The accuracy of the estimates will depend on the prediction power of $H$ estimating models. Comparison between the fitted base and generalized $H$ estimating model for $H$ predictions of forest types indicated that for montane, mangrove, and wetlands, parameters for $P R_{A}$ were not significant suggesting that when $B A$ enters into the model nonlinearly, the model explains most of $H$ and $P R_{A}$ remain redundant. We dropped models having insignificant parameter for $P R_{A}$. It was expected that the pattern displayed by $P R_{A}$ to the lowland and humid montane forest to be the same as shown in Table 5 (positive and significant $P R_{A}$ parameters). However, while $P R_{A}$ was important for lowland forests in modifying $H-D$ allometry, it was not the case for humid montane forest. This may be explained by wide distribution scale of lowland forests to various precipitation patterns [58]. The fact that humid montane forests occur in wetter areas, i.e., leeward of eastern, southern and northern mountains (elevated areas and therefore low evapotranspiration; [43]), may explain why $P R_{A}$ were found insignificant to $H-D$ allometry.

As expected climate and forest structure variables were highly significant when fitting generalized regional $H$ estimating model since the modelling data covers large spatial 
variability in terms of climate and forest structure which consequently affects $H-D$ allometry (e.g., [2]). However, the magnitude of their contribution in explaining $H-D$ allometry varied. The residuals of generalized regional model with $B A$ included were far more balanced than base model. Addition of $P R_{A}$ on top of $B A$ did not improve the residual plots. This is further indicated by $P E \%$ values where generalized regional model with $B A$ had $P E \%$ below $12 \%$ except for grassland and wetland forest. These findings indicate that generalized regional model can adequately predict $H$ of trees found in the studied forests with exception of few when climate and forest stand variables are available [2]. For improved accuracy, however, forest specific generalized $H$ estimating models are recommended. Forest specific $H$ estimating model is recommended when climate and stand variables information is not available.

\section{Conclusion}

The $H-D$ allometry was developed with comprehensive data set collected from NFI covering eight main forest types in Tanzania Mainland. The findings indicated that spatial variability in $H-D$ allometry in Tanzania Mainland is significant. The mean tree height tends to increase with the increase of mean precipitation $\left(P R_{A}\right)$. Total tree height increases with the increase in $B A$. The $B A$ in addition to $D$ was far more important explanatory variable than other climate and forest stand variables. We therefore confirm a significant contribution of climate and forest structure variables in modifying $H-D$ allometry. Consequently, generalized $H$ models turned out to be the best compared to base models. It is therefore recommended the forest specific generalized $H$ model to be applied when predicting $H$. When forest type information is not available, generalized regional model may be applied. Height base model may be applied when forest stand or climate information are missing.

\section{Data Availability}

The National Forest Inventory data also known as NAFORMA used to support the findings of this study were supplied with agreement with three institutions, i.e., National Carbon Monitoring Centre (NCMC), Tanzania Forest Service (TFS), and Tanzania Forestry Research Institute (TAFORI) who are custodian of the said data set. The data set cannot be made freely available. Requests for access to these data should be made through the following address: National Carbon Monitoring Centre, College of Forestry, Wildlife and Tourism, Sokoine University of Agriculture, P.O. Box 3009, Morogoro, Tanzania. E-Mail: NCMCTanzania@sua.ac.tz.

\section{Conflicts of Interest}

The authors declare that they have no conflicts of interest.

\section{Acknowledgments}

The authors wish to thank Tanzania Forest Service Agency (TFS) in the Ministry of Natural Resources and Tourism (MNRT) for availing the tree height-diameter data from the National Forest Assessments and Monitoring (NAFORMA) database to the INFORES project supported by Ministry of Foreign Affairs of Finland [grant number: 28235767 and ID: UHA2013-008402] which supported the process of data analysis and finally publishing the paper.

\section{References}

[1] J. Chave, M. Réjou-Méchain, A. Búrquez et al., "Improved allometric models to estimate the aboveground biomass of tropical trees," GCB Bioenergy, vol. 20, no. 10, pp. 3177-3190, 2014.

[2] T. R. Feldpausch, L. Banin, O. L. Phillips et al., "Height-diameter allometry of tropical forest trees," Biogeosciences Discussions, vol. 7, no. 5, pp. 7727-7793, 2010.

[3] E. Gómez-García, T. Fonseca, F. Crecente-Campo et al., "Height-diameter models for maritime pine in Portugal: a comparison of basic, generalized and mixed-effects models," iForest - Biogeosciences and Forestry, vol. 9, no. 1, pp. 72-78, 2016.

[4] E. W. Mauya, W. A. Mugasha, E. Zahabu, O. M. Bollandsås, and T. Eid, "Models for estimation of tree volume in the miombo woodlands of Tanzania," Southern Forests, vol. 67, no. 4, pp. 209219,2014

[5] J. J. Corral-Rivas, M. Barrio-Anta, O. A. Aguirre-Calderón, and U. Diéguez-Aranda, "Use of stump diameter to estimate diameter at breast height and tree volume for major pine species in El Salto, Durango (Mexico)," Forestry, vol. 80, no. 1, pp. 2940, 2007.

[6] L. E. Frelich, Predicting Dimensional Relationships For Twin Cities Shade Trees, 1992.

[7] H. Hasenauer, "Dimensional relationships of open-grown trees in Austria," Forest Ecology and Management, vol. 96, no. 3, pp. 197-206, 1997.

[8] S. A. O. Chamshama, A. G. Mugasha, and E. Zahabu, "Stand biomass and volume estimation for Miombo woodlands at Kitulangalo, Morogoro, Tanzania," Southern African Forestry Journal, vol. 200, pp. 59-70, 2004.

[9] J. Chave, C. Andalo, S. Brown et al., "Tree allometry and improved estimation of carbon stocks and balance in tropical forests," Oecologia, vol. 145, no. 1, pp. 87-99, 2005.

[10] W. A. Mugasha, E. E. Mwakalukwa, E. Luoga et al., "Allometric models for estimating tree volume and aboveground biomass in lowland forests of Tanzania," Journal of Forestry Research, vol. 2016, Article ID 8076271, 13 pages, 2016.

[11] A. D. Friend, "The prediction and physiological significance of tree height," in Vegetation Dynamics \& Global Change, pp. 101115, Springer, Boston, MA, USA, 1993.

[12] E. M. Nogueira, P. M. Fearnside, B. W. Nelson, R. I. Barbosa, and E. W. H. Keizer, "Estimates of forest biomass in the Brazilian Amazon: New allometric equations and adjustments to biomass from wood-volume inventories," Forest Ecology and Management, vol. 256, no. 11, pp. 1853-1867, 2008.

[13] N. Vizcaíno-Palomar, I. Ibáñez, M. Benito-Garzón, S. C. González-Martínez, M. A. Zavala, and R. Alía, "Climate and population origin shape pine tree height-diameter allometry," New Forests, vol. 48, no. 3, pp. 363-379, 2017. 
[14] W. A. Mugasha, O. M. Bollandsås, R. E. Malimbwi et al., "Allometric models for prediction of above- and belowground biomass of trees in the miombo woodlands of Tanzania," Forest Ecology and Management, vol. 310, pp. 87-101, 2013.

[15] B. Husch, T. W. Beers, and J. A. Kershaw Jr., Forest Mensuration, John Wiley \& Sons, 2002.

[16] D. C. Bragg, "An improved tree height measurement technique tested on mature southern pines," Southern Journal of Applied Forestry, vol. 32, pp. 38-43, 2008.

[17] M. O. Hunter, M. Keller, D. Victoria, and D. C. Morton, "Tree height and tropical forest biomass estimation," Biogeosciences, vol. 10, no. 12, pp. 8385-8399, 2013.

[18] R. O. Curtis, "Height-diameter and height-diameter-age equations for second-growth douglas-fir," Forest Science, vol. 13, pp. 365-375, 1967.

[19] S. Huang, S. J. Titus, and D. P. Wiens, "Comparison of nonlinear height-diameter functions for major Alberta tree species," Canadian Journal of Forest Research, vol. 22, no. 9, pp. 12971304, 1992.

[20] L. Mehtätalo, "Height-Diameter models for scots pine and birch in Finland," Silva Fennica, vol. 39, pp. 55-66, 2005.

[21] L. Mehtätalo, S. de-Miguel, and T. G. Gregoire, "Modeling height-diameter curves for prediction," Canadian Journal of Forest Research, vol. 45, pp. 826-837, 2015.

[22] A. Ledo, K. I. Paul, D. F. R. P. Burslem et al., "Tree size and climatic water deficit control root to shoot ratio in individual trees globally," New Phytologist, vol. 217, no. 1, pp. 8-11, 2018.

[23] E. R. Lines, M. A. Zavala, D. W. Purves, and D. A. Coomes, "Predictable changes in aboveground allometry of trees along gradients of temperature, aridity and competition," Global Ecology and Biogeography, vol. 21, no. 10, pp. 1017-1028, 2012.

[24] F. R. López-Serrano, A. García-Morote, M. Andrés-Abellán, A. Tendero, and A. Del Cerro, "Site and weather effects in allometries: A simple approach to climate change effect on pines," Forest Ecology and Management, vol. 215, no. 1-3, pp. 251270, 2005.

[25] M. G. Ryan, N. Phillips, and B. J. Bond, "The hydraulic limitation hypothesis revisited," Plant, Cell \& Environment, vol. 29, no. 3, pp. 367-381, 2006.

[26] M. G. Ryan and B. J. Yoder, "Hydraulic limits to tree height and tree growth," Bioscience, vol. 47, no. 4, pp. 235-242, 1997.

[27] N. D. Burgess, B. Bahane, T. Clairs et al., "Getting ready for REDD+ in Tanzania: a case study of progress and challenges," Oryx, vol. 44, no. 3, pp. 339-351, 2010.

[28] W. A. Mugasha, O. M. Bollandsås, and T. Eid, "Relationships between diameter and height of trees in natural tropical forest in Tanzania," Southern Forests, vol. 75, 2013.

[29] B. Zeide and C. Vanderschaaf, "The effect of density on the height-diameter relationship," General Technical Reports SRS-48, Department of Agriculture, Forest Service, Southern Research Station, Asheville, NC, USA, 2002.

[30] E. Zahabu, T. Raphael, S. A. O. Chamshama, S. Iddi, and R. E. Malimbwi, "Effect of spacing regimes on growth, yield, and wood properties of tectona grandis at Longuza forest plantation, Tanzania," International Journal of Forestry Research, vol. 2015, Article ID 469760, 6 pages, 2015.

[31] M. J. Opulukwa, K. F. S. Hamza, and Y. H. M. B. Malende, "Inventory of dalbergia melanoxylon (mpingo) in the southern part of tanzania: the case of nachingwea," African Study Monographs, pp. 1-10, 2002.
[32] R. Malimbwi and A. G. Mugasha, "Reconnaissance inventory of handeni forest reserve in Tanga, Tanzania," Dar es Sallam, Tanzania, 2001.

[33] L. Mbwambo, S. Valkonen, and V. Kuutti, Working Papers of The Finnish Forest Research Institute 98 Research And Development for Sustainable Management of Semiarid Miombo Woodlands in East Africa Structure And Dynamics of Miombo Woodland Stands at Kitulangalo Forest Reserve, Tanzania, Working Papers of the Finnish Forest Research Institute, 2008.

[34] A. Mathias and Augustine., Models for Estimating Tree Volume, Above-And Belowground Biomass for Acacia-Commiphora Woodlands in Same District, Tanzania, 2015.

[35] M. A. Njana, O. M. Bollandsås, T. Eid, E. Zahabu, and R. E. Malimbwi, "Above- and belowground tree biomass models for three mangrove species in Tanzania: a nonlinear mixed effects modelling approach," Annals of Forest Science, vol. 73, no. 2, pp. 353-369, 2016.

[36] MNRT, National Forest Resources Monitoring and Assessment of Tanzania Mainland, MNRT, Dar es Salaam, Tanzania, 2015.

[37] M. Näslund, "Skogsförsöksanstaltens gallringsförsök i tallskog," no. 29: 1, 1936.

[38] W. R. Wykoff, N. L. Crookston, and A. R. Stage, "User's Guide to the Stand Prognosis Model," UT: U.S. Department of Agriculture, Forest Service, Intermountain Forest and Range Experiment Station INT-133, 1982.

[39] M. Prodan, Forest Biometrics, Pergamon Press, 1968.

[40] F. J. Richards, "A flexible growth function for empirical use," Journal of Experimental Botany, vol. 10, pp. 290-301, 1959.

[41] D. A. Ratkowsky, Handbook of Nonlinear Regression Models, M. Dekker, Ed., 1990.

[42] W. Weibull, A Statistical Distribution Function of Wide Applicability, 1951.

[43] P. K. T. Munishi and T. H. Shear, "Carbon storage in afromontane rain forests of the eastern arc mountains of Tanzania: their net contribution to atmospheric carbon," Journal of Tropical Forest Science, vol. 16, no. 1, pp. 78-93, 2004.

[44] MNRT, "National forestry resources monitoring and assessment of Tanzania (NAFORMA)," in Field Manual - Biophysical Survey, MNRT, Dar es Sallam, Tanzania, 2010.

[45] FAO, Global Forest Resources Assessment 2010 - Specification of National Reporting Tables for FRA 2010, FRA Work, Pap. No 135 51, 2007.

[46] P. K. T. Munishi, "The eucalyptus controversy in Tanzania," in Proceedings of the TAF Annual General Meeting (AGM) 23rd-24th, 2007.

[47] E. Tomppo, R. Malimbwi, M. Katila et al., "A sampling design for a large area forest inventory: Case Tanzania," Canadian Journal of Forest Research, vol. 44, no. 8, pp. 931-948, 2014.

[48] S. E. Fick and J. H. Robert, "WorldClim 2: new 1-km spatial resolution climate surfaces for global land areas," International Journal of Climatology, vol. 37, no. 12, pp. 4302-4315, 2017.

[49] J. K. Vanclay, Modelling Forest Growth And Yield: Applications to Mixed Tropical Forests, vol. 537, School of Environment, Science and Engineering Papers, 1994.

[50] A. Fayolle, G. J. Loubota Panzou, T. Drouet et al., "Taller trees, denser stands and greater biomass in semi-deciduous than in evergreen lowland central African forests," Forest Ecology and Management, vol. 374, pp. 42-50, 2016.

[51] E. Gómez-García, F. Crecente-Campo, B. Tobin, M. Hawkins, M. Nieuwenhuis, and U. Diéguez-Aranda, "A dynamic volume 
and biomass growth model system for even-aged downy birch stands in south-western Europe," Forestry, vol. 87, no. 1, pp. 165176, 2014.

[52] J. Pinheiro, D. Bates, S. DebRoy, D. Sarkar, and R. C. Team, "Linear and Nonlinear Mixed Effects Models," R Packag. version 3, 2007.

[53] R. C. Team, R: A Language And Environment for Statistical Computing, R Foundation for Statistical Computing, Vienna, Austria, 2014.

[54] W. A. Mugasha, O. M. Bollandsås, and T. Eid, "Corrigendum to Relationships between diameter and height of trees in natural tropical forest in Tanzania (Southern Forests, (2013), 75, 4(221237), http://dx.doi.org/10.2989/20702620.2013.824672)," Southern Forests, vol. 76, no. 4, 2014.

[55] J. L. F. Batista, H. T. Z. Do Couto, and M. Marquesini, "Performance of height-diameter relationship models: Analysis in three forest types," Scientia Forestalis, no. 60, pp. 149-163, 2001.

[56] J. Fang, A. Chen, C. Peng, S. Zhao, and L. Ci, "Changes in forest biomass carbon storage in China between 1949 and 1998," Science, vol. 292, no. 5525, pp. 2320-2322, 2001.

[57] M. A. S. da Scaranello, L. F. Alves, S. A. Vieira, P. B. de Camargo, C. A. Joly, and L. A. Martinelli, "Height-diameter relationships of tropical Atlantic moist forest trees in southeastern Brazil," Scientia Agricola, vol. 69, no. 1, pp. 26-37, 2012.

[58] P. Binggeli, "Trees of amani nature reserve, NE Tanzania," African Journal of Ecology, vol. 39, no. 3, pp. 324-324, 2001.

[59] S. C. Thomas, A. R. Martin, and E. E. Mycroft, "Tropical trees in a wind-exposed island ecosystem: Height-diameter allometry and size at onset of maturity," Journal of Ecology, vol. 103, no. 3, pp. 594-605, 2015.

[60] Y. M. Ngaga, Forest Plantations and Woodlots in Tanzania, African Forest Forum, vol. 16, 2011.

[61] K. M. Becklin, J. T. Anderson, L. M. Gerhart, S. M. Wadgymar, C. A. Wessinger, and J. K. Ward, "Examining plant physiological responses to climate change through an evolutionary lens," Plant Physiology, vol. 172, no. 2, pp. 635-649, 2016.

[62] S. J. Franks, J. J. Weber, and S. N. Aitken, "Evolutionary and plastic responses to climate change in terrestrial plant populations," Evolutionary Applications, vol. 7, no. 1, pp. 123-139, 2014.

[63] D. A. King, "Correlations between biomass allocation, relative growth rate and light environment in tropical forest saplings," Functional Ecology, vol. 5, no. 4, pp. 485-492, 1991.

[64] A. Takenaka, "A simulation model of tree architecture development based on growth response to local light environment," Journal of Plant Research, vol. 107, no. 3, pp. 321-330, 1994.

[65] C. D. Allen, A. K. Macalady, H. Chenchouni et al., "A global overview of drought and heat-induced tree mortality reveals emerging climate change risks for forests," Forest Ecology and Management, vol. 259, no. 4, pp. 660-684, 2010.

[66] A. Hamann and T. Wang, "Potential effects of climate change on ecosystem and tree species distribution in British Columbia," Ecology, vol. 87, no. 11, pp. 2773-2786, 2006.

[67] R. G. Pearson and T. P. Dawson, "Predicting the impacts of climate change on the distribution of species: Are bioclimate envelope models useful?" Global Ecology and Biogeography, vol. 12, no. 5, pp. 361-371, 2003.

[68] W. Thuiller, S. Lavorel, M. T. Sykes, and M. B. Araújo, "Using niche-based modelling to assess the impact of climate change on tree functional diversity in Europe," Diversity and Distributions, vol. 12, no. 1, pp. 49-60, 2006.
[69] G. Imani, F. Boyemba, S. Lewis et al., "Height-diameter allometry and above ground biomass in tropical montane forests: Insights from the Albertine Rift in Africa," PLoS ONE, vol. 12, no. 6, 2017.

[70] M. Ritchie, J. Zhang, and T. Hamilton, "Effects of stand density on top height estimation for ponderosa pine," Western Journal of Applied Forestry, vol. 27, no. 1, pp. 18-24, 2012.

[71] E. Assmann, The Principles of Forest Yield Study: Studies in The Organic Production, Structure, Increment, and Yield of Forest Stands, Pergamon Press, 1970.

[72] D. Dunning, A Site Classification for The Mixed-Conifer Selection Forests of The Sierra Nevada, vol. 19 of Res. Note 28, Department of Agriculture, Forest Service, California Forest and Range Experiment Station, Berkeley, CA, USA, 1942.

[73] F. S. Baker, "Stand density and growth," Journal of Forestry, vol. 51, pp. 95-97, 1953.

[74] F. Boyemba, S. Lewis, N. Le et al., "Height-diameter allometry and above ground biomass in tropical montane forests: Insights from the Albertine Rift in Africa," Plos One, pp. 1-20, 2017.

[75] K. T. Logan, "Growth of tree seedlings as affected by light intensity i. white birch, yellow birch," Sugar Maple and Silver Maple, 1965.

[76] H. A. L. Henry and L. W. Aarssen, “The interpretation of stem diameter-height allometry in trees: biomechanical constraints, neighbour effects, or biased regressions?" Ecology Letters, vol. 2, pp. 89-97, 1999.

[77] H. E. Burkhart and M. Tomé, "Indices of individual-tree competition," in Modeling Forest Trees and Stands, pp. 201-232, Springer, Dordrecht, Netherlands, 2012.

[78] K. Maleki, A. Kiviste, and H. Korjus, "Analysis of individual tree competition on diameter growth of silver birch in estonia," Forest Systems, vol. 24, Article ID e023, 2015.

[79] W. A. Mugasha, T. Eid, O. M. Bollandsås, and L. Mbwambo, "Modelling diameter growth, mortality and recruitment of trees in miombo woodlands of Tanzania," Southern Forests, vol. 79, 2017.

[80] J. Weiner, Competition among Plants, 1991. 

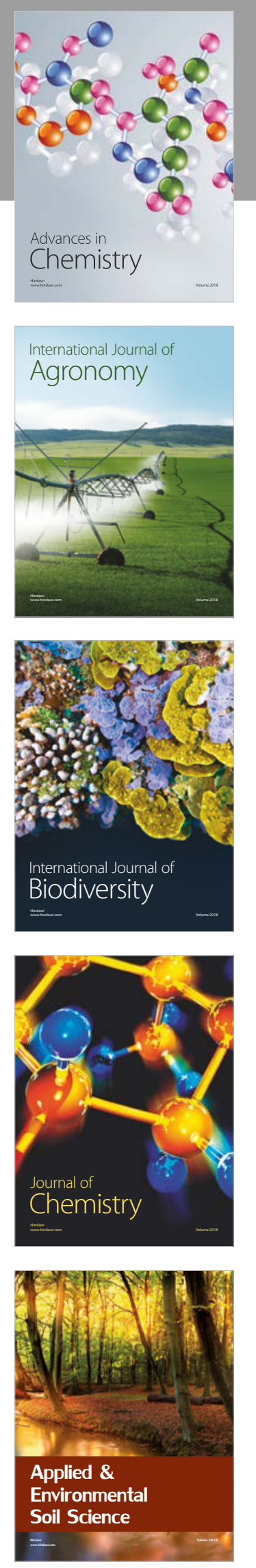

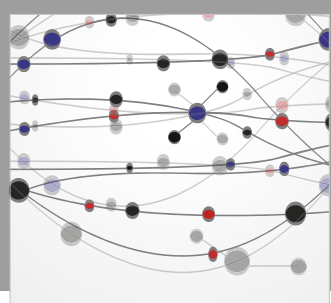

The Scientific World Journal

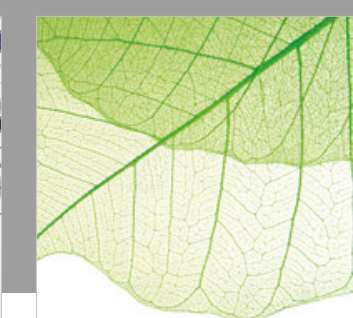

Journal of Botany

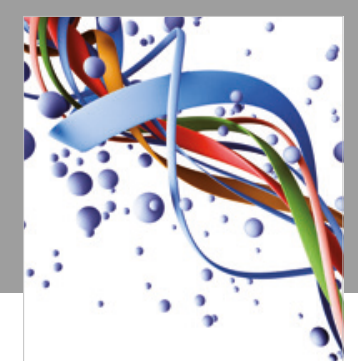

Scientifica

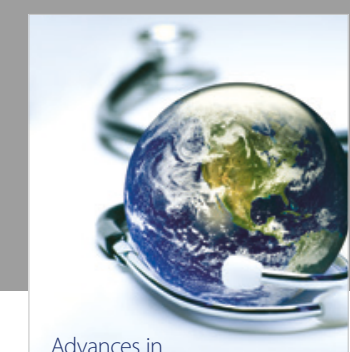

Public Health

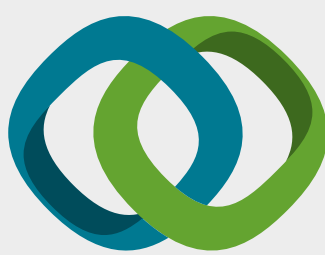

Hindawi

Submit your manuscripts at

www.hindawi.com
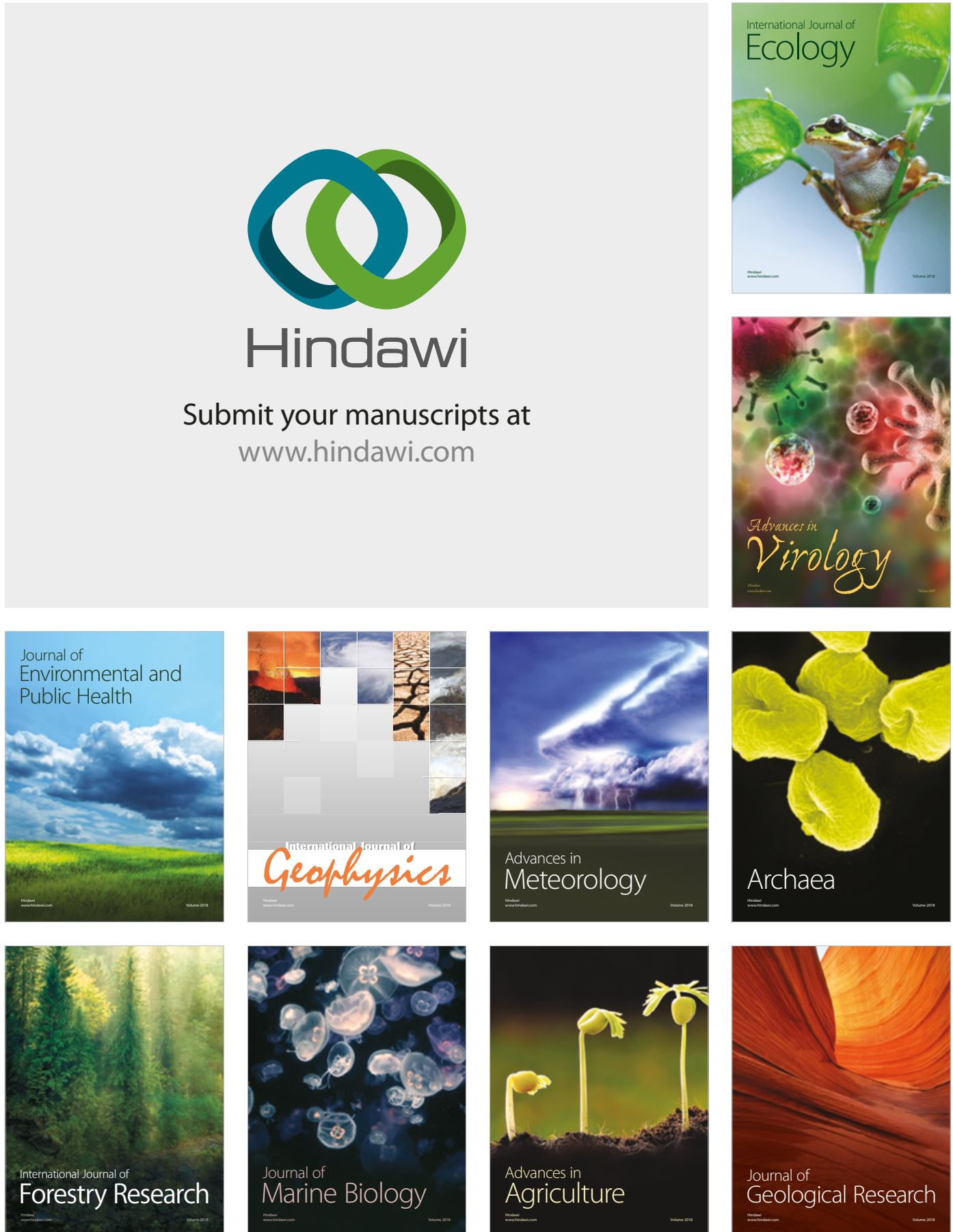

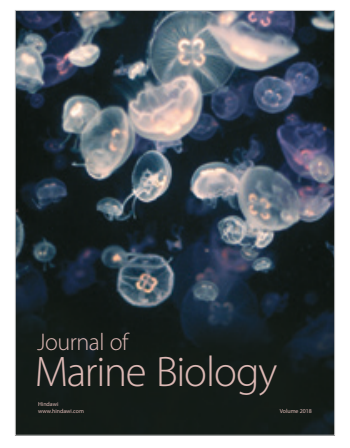

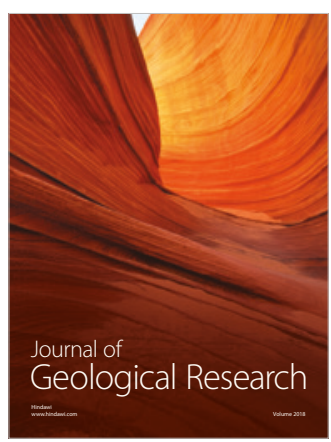

